\title{
On-body Transmission Single-band Diamond Dipole Antenna with Waveguide Jacke
}

\author{
M. A. Abdullah', M. K. A Rahim², N. A. Samsuri' ${ }^{3}$, K. Kamardin ${ }^{4}$ \\ ${ }_{1,2,3}$ Communication Engineering Department, Faculty of Electrical Engineering, University Technology Malaysia, 81310 \\ Johor Bahru, Johor, Malaysia \\ ${ }^{4}$ Advanced Informatics School, Universiti Teknologi Malaysia, Kuala Lumpur 54100, Malaysia \\ ${ }^{4}$ Wireless Communication Centre, Universiti Teknologi Malaysia, Kuala Lumpur 54100, Malaysia
}

\begin{tabular}{|c|c|}
\hline Article Info & ABSTRACT \\
\hline Article history: & This paper presents the investigation of on-body transmission single-band \\
\hline Received Dec 12, 2017 & $\begin{array}{l}\text { diamond dipole antenna with three different jackets. The jackets are named } \\
\text { as normal jacket, grounding jacket and waveguide jacket. The on-body }\end{array}$ \\
\hline Revised Feb 27, 2018 & transmission is measured using two flexible single-band antennas attach to \\
\hline Accepted Mar 23, 2018 & $\begin{array}{l}\text { the jackets. A man with the height of } 180 \mathrm{~cm} \text { and } 75 \mathrm{~kg} \text { weight becomes as a } \\
\text { model for the real measurement. The measurement is conducted in small }\end{array}$ \\
\hline Keywords: & $\begin{array}{l}\text { space area by using portable network analyzer with flexible network cable. } \\
\text { The measurement results show that the best performance for on-body }\end{array}$ \\
\hline Dipole & transmission is with waveguide jacket. $10 \mathrm{~dB}$ transmission improvement is \\
\hline Single-band & the normal jacket. It is found that the transmission of the antenna is also \\
\hline Transmission & depends on the antenna orientation and further transmission lossess occur \\
\hline Waveguide & when the antennas are placed above the grounding jacket. \\
\hline
\end{tabular}

Copyright $\odot 2018$ Institute of Advanced Engineering and Science. All rights reserved.

\section{Corresponding Author:}

Muhammad Azfar bin Abdullah, Communication Engineering Department, Faculty of Electrical Engineering,

University Technology Malaysia, 81310 Johor Bahru, Johor, Malaysia.

Email: azfar87@gmail.com

\section{INTRODUCTION}

Nowadays, human body has become a part of wearable wireless networking devices as the electronic devices become smaller and cheaper. Since human body becomes a part of communication network, the integration of wireless sensor network (WSN) and wireless personal area network (WPN) become body-centric wireless communication.

Due to complexity of the human body, many researchers around the world interested to investigate in this body-centric wireless communication area. Firstly, some fabric antennas have been investigated by [1]- [3] since 1999. They are using felt fabric as substrate and Zelt fabric as conducting element. However, the performance of the antenna deteroriated when the antenna is put above the human body [4]. The bulky size of coaxial port that has been used in [5-6] also is not suitable for wearable application.

Theoritycally, the main characteristic of an artificial magnetic conductor (AMC) to influence the propagation electromacnetic waves is in-phase reflection coeficient [7]. Previous researchers have presented that the AMC may reduce the backward radiation and improve the gain of the antenna [8]-[9]. Then, sheetlike waveguide sheet is proposed by [10]-[13], 16] to reduce the distortion from the human body. The waveguide sheet is consisted of array of AMC. The function of the sheet-like waveguide is to reduce the transmission losses between the antennas.

In this paper, two single-band textile diamond dipole antenna which are operating at $2.4 \mathrm{GHz}$ and $5.8 \mathrm{GHz}$ are used to investigate the S21 transmission above three different jackets; normal jacket, grounding 
jacket and waveguide jacket. S21 transmission is measured in horizontal and vertical orientation for all jackets. The performance of the transmission for the jackets are compared and discussed.

\section{MEASUREMENT SETUP}

Two single-band diamond dipole antennas which are operated at $2.4 \mathrm{GHz}$ and $5.8 \mathrm{GHz}$ respectively have been used to be incorporated with three different jackets as shown in Figure 1. The jackets are made of fleece fabric named as normal jacket, grounding jacket and waveguide jacket. Normal jacket is a plain jacket while grounding jacket has attached with full ground plane fabric. The waveguide jacket is an array of AMC design from my previous work [4].

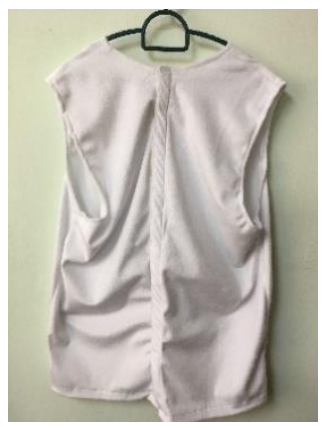

(a) Normal jacket

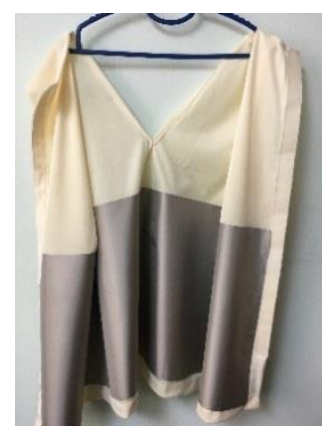

(b) Grounding jacket

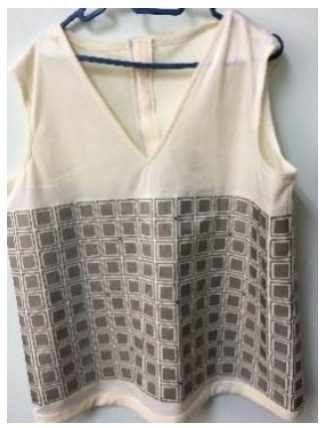

(c) Waveguide jacket

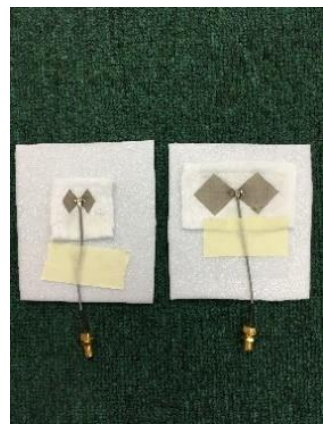

(d) Antennas

Figure 1. Overview of antennas and three different jackets

The orientation of the antenna is investigated above the jackets. The antennas are placed vertically and horizontaly above each jacket as shown in Figure 2. One of the antennas is placed in the middle of the jacket which acts as a transmitter (Tx) while the other antenna (Rx) position is varied at eight different locations. The locations are labelled alphabetically from A to $\mathrm{H}$ as shown in Figure 3. The distance between the antenns is fixed at $14 \mathrm{~cm}$.

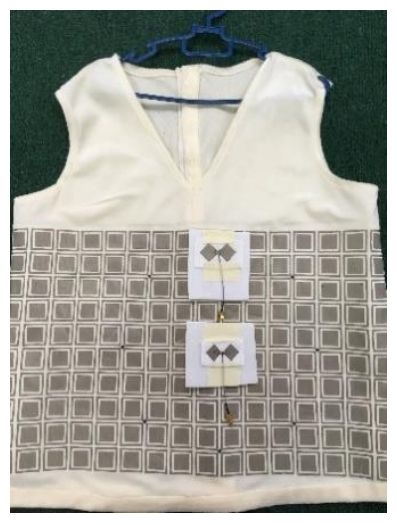

(a) Horizontal polarization

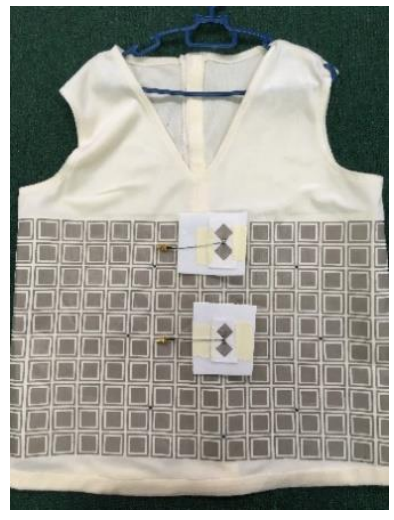

(b) Vertical polarization

Figure 2. Antenna polarization 


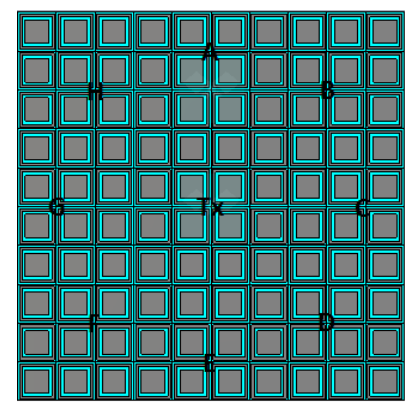

Figure 3. Positions of the antenna (Rx)

The experiment is conducted in small space area. A man becomes a model to wear the jackets. During the experiment, he stands up and the transmission between the antennas is measured as shown in Figure 4 . The gap between both antennas and the jacket is set to $3 \mathrm{~mm}$ by using a foam $\left(\sigma_{r}=1\right)$. Portable network analyser is used to measure the transmission performance of the antennas.

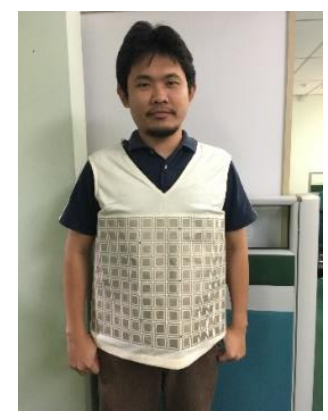

Figure 4. Snapshot of the experiment setup

\section{RESULTS AND DISCUSSIONS}

The results are divided and analyzed into two sub chapter. The first sub chapter explains about 2.4 $\mathrm{GHz}$ antenna transmission while the 2 nd sub chapter elobrates about $5.8 \mathrm{GHz}$ antenna transmission.

\section{1. $S_{21}$ Transmission of $2.4 \mathrm{GHz}$ Textile Diamond Dipole Antenna}

The S21 on-body transmissions of the antenna with three jackets were investigated. Graph in Figure 4 presents the S21 transmission of $2.4 \mathrm{GHz}$ antenna with normal jacket in horizontal orientation. Figure 5(a) and Figure 5(b) denote the vertical arrangement respectively. Graphs in Figure 6 depict the measured S21 of antennas with grounding jacket while Graph in Figure 7 represents the measured S21 of antennas with waveguide jacket. Figures 6(a) and 7(a) represent for horizontal antenna orientation and figures 6(b) and 7(b) represent vertical antenna orientation.

When the antenna is placed horizontally, good transmission of the antenna observed at position A and E. For horizontal orientation, the S21 peaks are $-32 \mathrm{~dB}$ and $-33 \mathrm{~dB}$ for position $\mathrm{A}$ and E. Position $\mathrm{C}$ and $\mathrm{G}$ represent parallel arrangement in vertical orientation with S21 peaks at $-30 \mathrm{~dB}$ and $-32 \mathrm{~dB}$ at resonance. Graphs in Figure 5 show no transmission occurs between the antennas. The S21 peaks at $-60 \mathrm{~dB}$ for both horizontal and vertical orientation which is at noise level. Finally positions A and E represent parallel arrangement in horizontal orientation with S21 peaks at $-24 \mathrm{~dB}$ and $-20 \mathrm{~dB}$ above the waveguide jacket while positions $C$ and $G$ in vertical orientation with $S 21$ peaks at $-24 \mathrm{~dB}$ and $-24 \mathrm{~dB}$.

Graphs in Figure 8 show the comparison of measured S21 results from Figure 5 to 7 . The best performance of S21 transmission from graphs in Figure 5 to Figure 7 is compared. It shows that the S21 peaks are improved by $8 \mathrm{~dB}$ and $13 \mathrm{~dB}$ at resonance for horizontal orientation. For vertical horizontal, $6 \mathrm{~dB}$ and $8 \mathrm{~dB}$ improvement is achieved when the antenna is placed above the waveguide jacket. When the antennas are placed above the normal jacket, the transmission is disturbed by the presence of human body. The waveguide jacket acts as a path for the wave to propagate between the antennas and improve the transmission. 


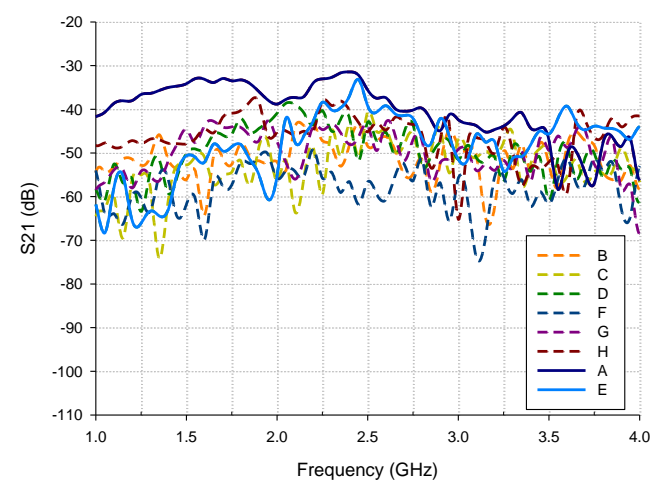

(a) Horizontal orientation

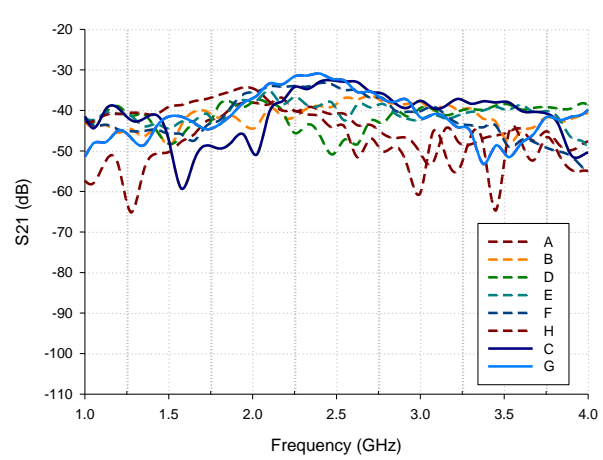

(b) Vertical orientation

Figure 5. Measured $\mathrm{S}_{21}$ of $2.4 \mathrm{GHz}$ textile diamond dipole above normal jacket

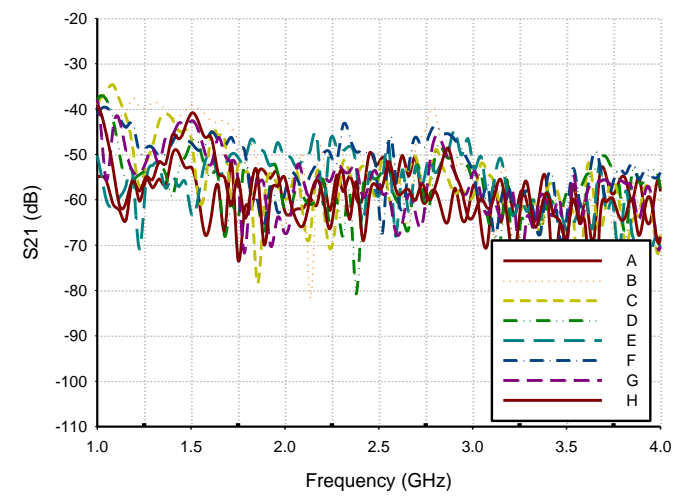

(a) Horizontal orientation

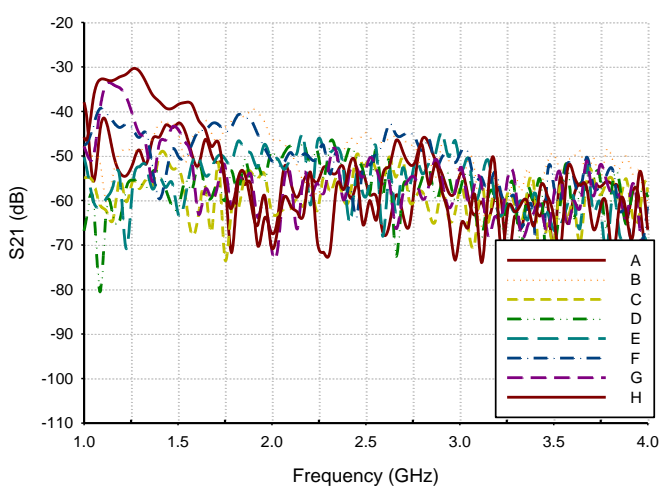

(b) Vertical orientation

Figure 6. Measured $\mathrm{S}_{21}$ of $2.4 \mathrm{GHz}$ textile diamond dipole above grounding jacket

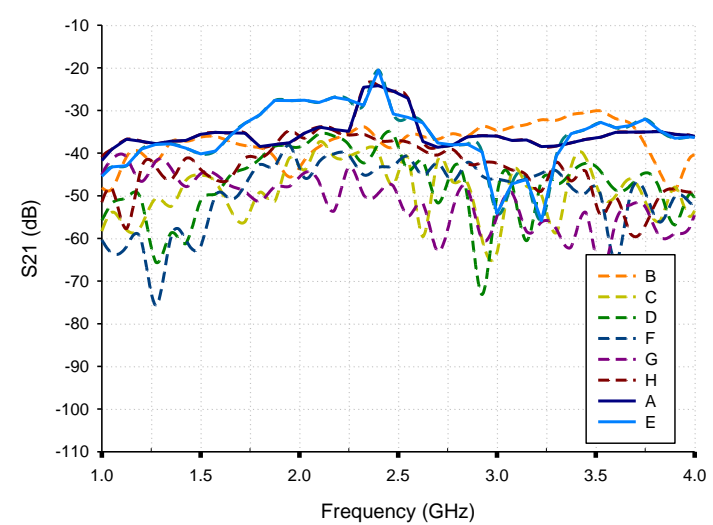

(a) Horizontal orientation

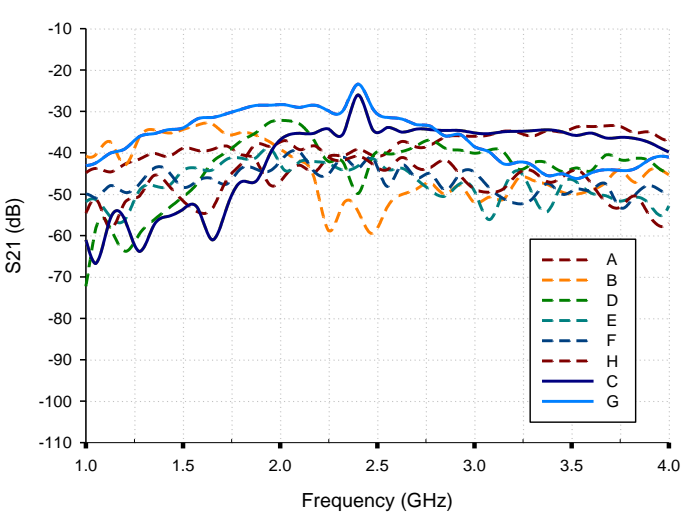

(b) Vertical orientation

Figure 7. Measured $\mathrm{S}_{21}$ of $2.4 \mathrm{GHz}$ textile diamond dipole above waveguide jacket 


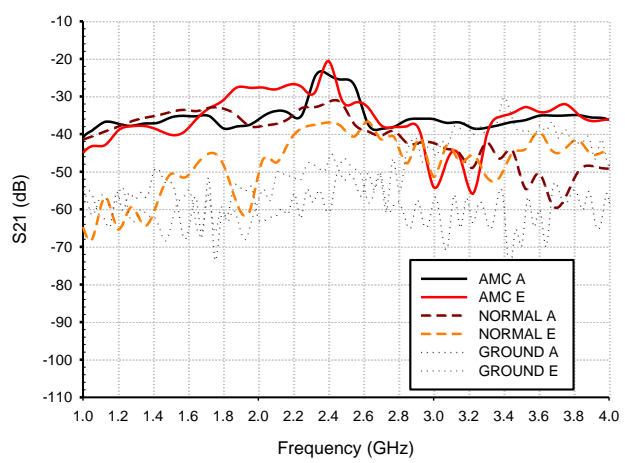

(a) Horizontal orientation

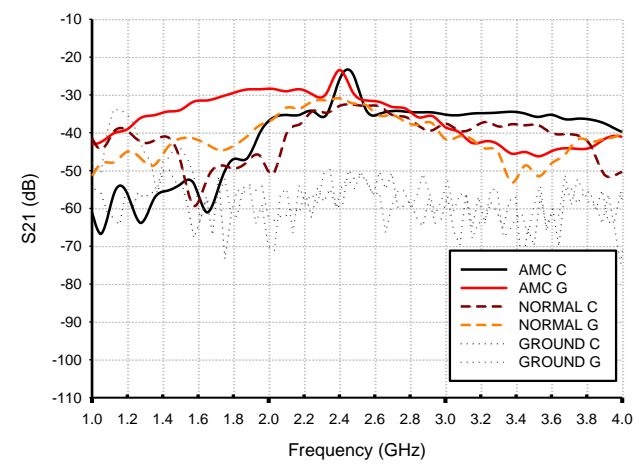

(b) Vertical orientation

Figure 8. Comparison of Measured $\mathrm{S}_{21}$ of $2.4 \mathrm{GHz}$ textile diamond dipole above different jackets

\section{2. $S_{21}$ Transmission of $5.8 \mathrm{GHz}$ Textile Diamond Dipole Antenna}

The measured $S_{21}$ transmissions are plotted in Figure 9 to Figure 11 for antenna above normal jacket, grounding jacket and waveguide jacket. Figure 9(a), 10(a) and 11(a) show the $5.8 \mathrm{GHz}$ diamond dipole 's transmission results in horizontal orientation while Figure 9(b), 10(b) and 11(b) depict the vertical horizontal.

Among the 8 positions varied, the best transmission is obtained when the antenna placed in parallel arrangement. For horizontal orientation, positions A and E represent the parallel arrangement and position C and $\mathrm{G}$ for vertical orientation. When the antennas are placed above the grounding jacket, the transmission occurs at the noise floor level. Transmission improvements at resonance $5.8 \mathrm{GHz}$ are observed at both horizontal and vertical orientations. From the horizontal orientation results, the $S_{21}$ peaks are $-28 \mathrm{~dB}$ and $30 \mathrm{~dB}$ with improvement of $10 \mathrm{~dB}$ and $8 \mathrm{~dB}$ from the transmission above the normal jacket. The comparison $\mathrm{S}_{21}$ results in vertical orientation are shown in Figure 12(b). The $\mathrm{S}_{21}$ peaks are $-37 \mathrm{~dB}$ and $-34 \mathrm{~dB}$ for position $\mathrm{C}$ and $\mathrm{G}$ above the normal jacket while $-28 \mathrm{~dB}$ for both position $\mathrm{C}$ and $\mathrm{G}$ above the waveguide jacket.

From the presented results, the presence of waveguide jacket improves the antennas' transmission compared to normal jacket. The structures of the waveguide jacket itself which is articifial magnetic conductor (AMC) help the wave to propogate through it.

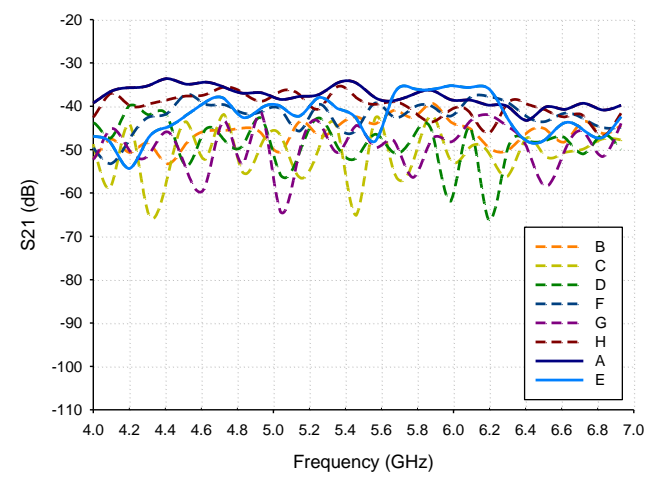

(a) Horizontal orientation

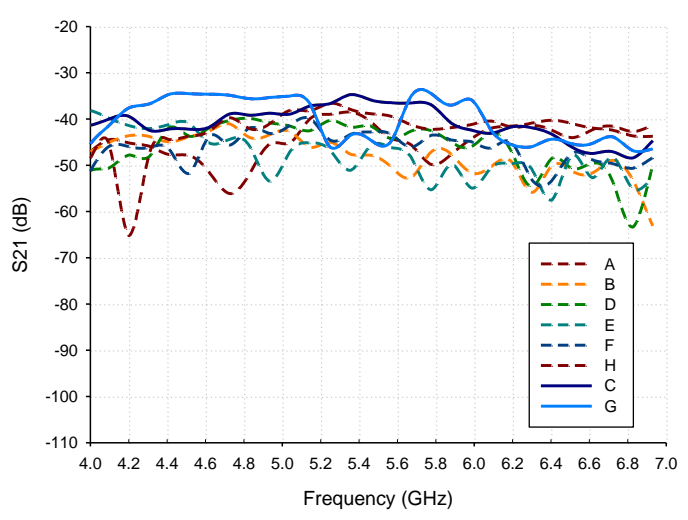

(b) Vertical orientation

Figure 9. Measured $\mathrm{S}_{21}$ of $5.8 \mathrm{GHz}$ textile diamond dipole above normal jacket 


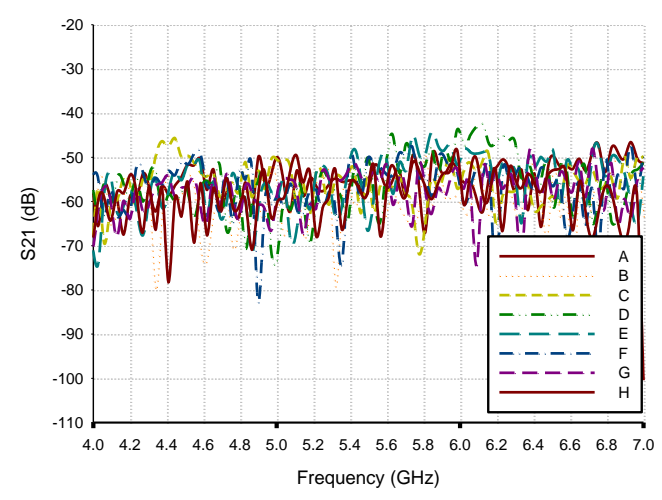

(a) Horizontal orientation

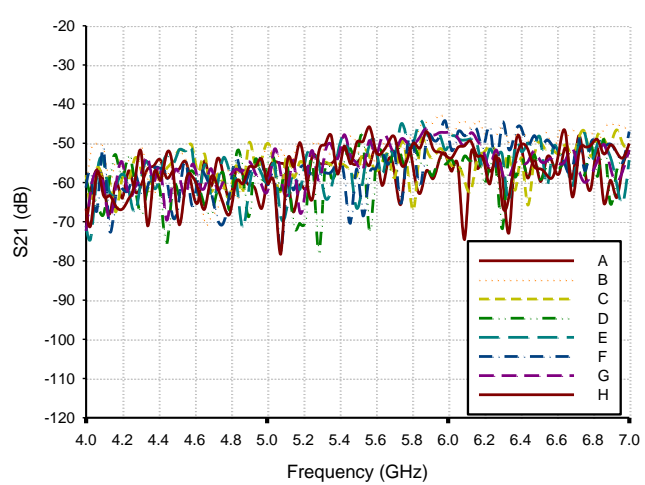

(b) Vertical orientation

Figure 10. Measured $S_{21}$ of $5.8 \mathrm{GHz}$ textile diamond dipole above grounding jacket

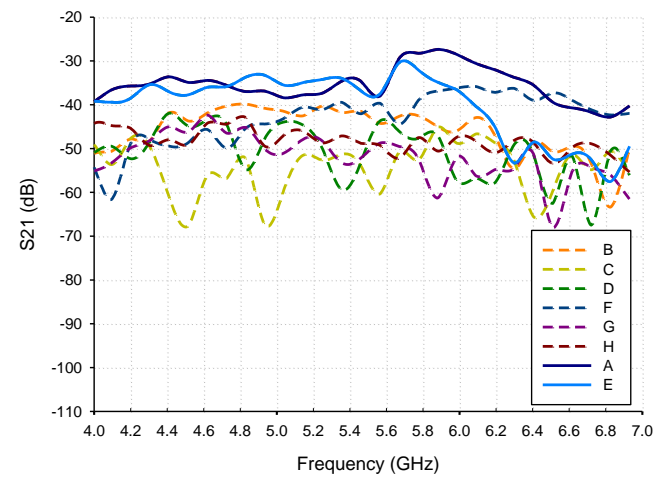

(a) Horizontal orientation

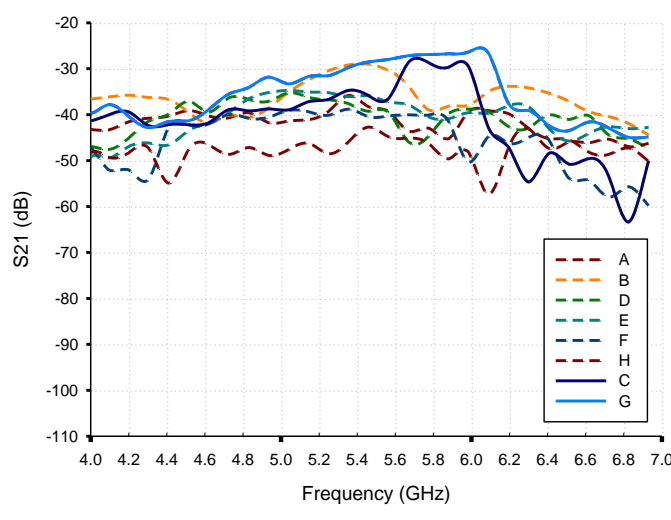

(b) Vertical orientation

Figure 11. Measured $\mathrm{S}_{21}$ of $5.8 \mathrm{GHz}$ textile diamond dipole above waveguide jacket



(a) Horizontal orientation

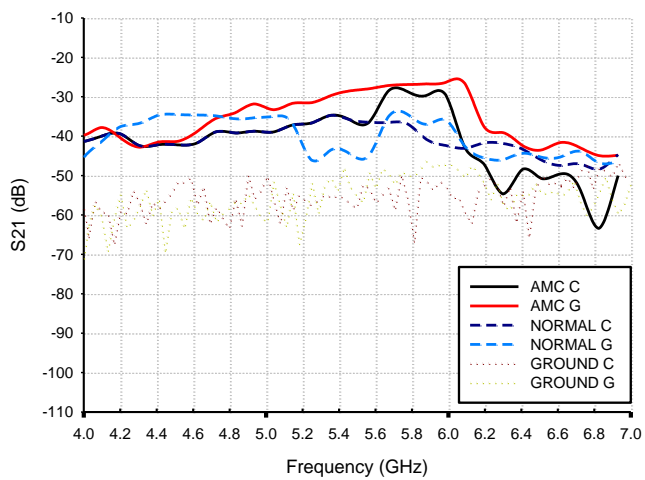

(b) Vertical orientation

Figure 12. Comparison of measured $\mathrm{S}_{21}$ of $5.8 \mathrm{GHz}$ textile diamond dipole above different jackets 


\section{CONCLUSION}

In conclusion, two single-band textile diamond dipole antenna with normal jacket, grounding jacket and waveguide jacket have been measured and investigated. The position of the antenna determined the transmission of the antenna. $10 \mathrm{~dB}$ improvement when both antennas in the same. The waveguide jacket provides clear transmission path and reduces transmission loss. The in-phase reflection characteristic in waveguide jacket is predicted to enhance the transmission between the antennas. Meanwhile, the ground jacket is not suitable for antenna propagation as presented in the results.

\section{ACKNOWLEDGEMENTS}

The authors wish to thank the Research Management Centre, Faculty of Electrical Engineering, Universiti Teknologi Malaysia (UTM) and the Malaysian Ministry of Education (MOE) for providing the Grant (Vote No: 4F883 and 12H08).

\section{REFERENCES}

[1] P. Salonen, et al., "A small planar inverted-F antenna for wearable applications," in Wearable Computers, 1999. Digest of Papers. The Third International Symposium on, 1999, pp. 95-100.

[2] S. Subramaniam and B. Gupta, "Design and Development of Body-Worn Applications and its Performance Study Under Flat and Bent Positions," Microw. Opt. Technol. Lett., vol. 53, no. 9, pp. 2004-2011, 2011.

[3] M. Tanaka and J. Jae-Hyeuk, "Wearable microstrip antenna," in Antennas and Propagation Society International Symposium, 2003. IEEE, 2003, pp. 704-707 vol.2.

[4] Muhammad Azfar Abdullah, Mohamad Kamal A.Rahim, Mohd Ezwan Jalil, Noor Asmawati Samsuri,Nor Asniza Murad, "Integrated Two Textile Dipole Antenna with dual band Artificial Magnetic conductor",7th European Conference on Antenna and propagation (Eucap 2013), Gothenburg, Sweden, 8 - 12 April 2013

[5] L. Liu, S. Zhu, and R. Langley, "Dual-band Triangular Patch Antenna with Modified Ground Plane," Electron Lett., vol. 43, no. 3, pp. 5-6, 2007.

[6] L. Ma, R. M. Edwards, and W. G. Whittow, "A Notched Hand Wearable Ultra Wideband W Printed Monopole Antenna for Sporting Activities," in Loughborough Antennas \& Propagation Conference, 2008, pp. 397-400.

[7] Muhammad Azfar Abdullah, Mohamad Kamal A.Rahim, Mohd Ezwan Jalil, Noor Asmawati Samsuri,Nor Asniza Murad, "Integrated Two Textile Dipole Antenna with dual band Artificial Magnetic conductor", 7th European Conference on Antenna and propagation (Eucap 2013), Gothenburg, Sweden, $8-12$ April 2013

[8] S. Zhu and R. Langley, "Dual-Band Wearable Textile Antenna on an EBG Substrate," IEEE Trans. Antennas Propag., vol. 57, no. 4, pp. 926-935, 2009

[9] M. S. Pimenta, F. Ferrero, P. Brachat, P. Ratajczak, R. Staraj, and J. M.Ribero, "Textile Artificial Magnetic Conductor for GPS Applications, ” in 6th European Conference on Antennas and Propagation (EuCAP), 2011, pp. 2884-2886

[10] K. Eom and H. Arai, 'Smart suit: wearable sheet-like waveguide bodycentric wireless communications', Eur. Wire. Tech. Conf., pp 1-4, 2010.

[11] K. Eom and H. Arai, 'Smart Blanket: Flexible and Easy to Couple Waveguide', IEEE Topical Conf. on Biomed. Wire. Tech., Net., and Sens. Sys., pp 15-18, 2011

[12] K. Kamardin, M. K. A. Rahim, P. S Hall, N. A. Samsuri, M. E. Jalil and M. Z. Anuar, "Textile Waveguide Sheet with Artificial Magnetic Conductor Structures for Body Centric Wireless Communication," in Asia-Pacific Conference in Applied Electromagnetic (APACE 2012), Melaka, Malaysia, 2012, pp. 257-261 K. Eom and H. Arai, "Wireless power transfer using sheet-like waveguide," in Antennas and Propagation, 2009. EuCAP 2009. 3rd European Conference on, 2009, pp. 3038-3041.

[13] M. A. Abdullah, M. K. A. Rahim, and N. A. Samsuri On-Body Communication System Transmission Enhancement Using a Dual-Band Textile Artificial Magnetic Conductor Adv. Sci. Lett. 23, 1129811301

[14] Maizatun Muhamad, Maisarah Abu, Zahriladha Zakaria, Hasnizom Hassan, "Novel Artificial Magnetic Conductor for 5G Application,' Indonesian Journal of Electrical Engineering and Computer Science (IJEECS). Vol. 5, No. 3, March 2017, pp. $636-642$

[15] Emad Shehab Ahmed, "Wearable Conformal Antennas for 2.4 GHz Wireless Body Area Networks," TELKOMNIKA (Telecommunication, Computing, Electronics and Control), Vol.11, No.1, March 2013, pp. 175 180 ISSN: 1693-6930 
[16] Adel Y. I. Ashap ${ }^{1}$, Z. Z. Abidin ${ }^{2}$, S.H. Dahlan ${ }^{3}$, H. A. Majid ${ }^{4}$, S.K. Yee ${ }^{5}$, Gameel Saleh ${ }^{6}$, Norun Abdul Malek "Flexible Wearable Antenna on Electromagnetic Band Gap using PDMS substrate," TELKOMNIKA (Telecommunication, Computing, Electronics and Control), Vol.15, No.3, September 2017, pp. 1454 1460 ISSN: 1693-6930, accredited A by DIKTI, Decree No: 58/DIKTI/Kep/2013

\section{BIOGRAPHIES OF AUTHORS}

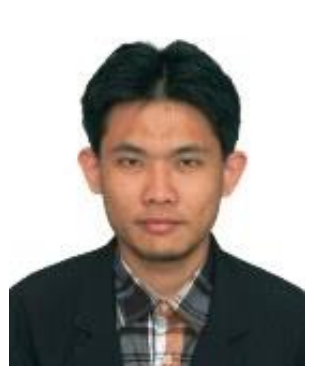

Muhammad Azfar bin Abdullah received the B Eng. Degree in Electrical Engineering majoring in Telecommunication from University Technology Malaysia in 2010. From 2010 to 2011, he worked as a process engineer at Infineon Technologies Berhad in Kulim Kedah. HE obtained hi M. Eng Electrical Engineering from University Technology Malaysia in 2014. Currently he is Studying PhD degrees in Electrical Engineering from University Technology Malaysia. During his study, he has published more than 10 articles in conference papers. His research interest includes the areas of designing antenna, artificial magnetic conductr and wearable application. Muhammad Azfar bin Abdullah is a member of Board of Engineer Malaysia (BEM) and a member of IEEE (MIEEE).

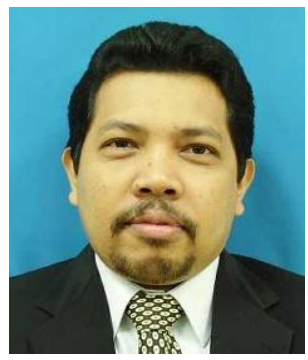

Mohamad Kamal A Rahim received the B Eng. degree in Electrical and Electronic Engineering from University of Strathclyde, UK, in 1987. From 1987 to 1989, he worked as a Management Trainee at Sime Tyres Mergong Alor Star Kedah and Production Supervisor at Sime Shoes in Kulim Kedah. In 1989, he joined the Department of Communication Engineering, Faculty of Electrical Engineering Universiti Teknologi Malaysia Kuala Lumpur as an Assistant Lecturer A. He obtained his M.Eng Science from University of New South Wales Australia in 1992 and PhD degrees in Electrical Engineering from University of Birmingham UK in 2003. After he received his Master he was appointed as a Lecturer at Faculty of Electrical Engineering. In 2005 he was appointed as a senior lecturer and in 2007 he was appointed as Assoc Professor at the faculty. Now he is the Professor in RF and Antenna at Faculty of Electrical Engineering Universiti Teknologi Malaysia. His research interest includes the areas of design of Dielectric resonator antennas, microstrip antennas, small antennas, microwave sensors, RFID antennas for readers and tags, Multi-function antennas, microwave cicuits, EBG, artificial magnetic conductors, metamaterials, phased array antennas, computer aided design for antennas and design of millimeter frequency antennas. He has published over 200 articles in journals and conference papers. He is a co author of a book title basic principle telecommunication and several book chapters and editor of three book chapters. He has been appointed as a reviewer for several journals papers at National and International level. Thus far, he has reviewed and edited more than 100 papers. In year 2012 he was awarded for the highest impact factor journal in Information and Communication Research Alliance (IcRA) during CITRA KARISMA 2012. Currently he is having two research grant from MOHE (ERGS and PRGS), one from MOSTI which is EScience, three from International Grant which is MOTOROLA , two from Research University Grant which is Tier 1 and Tier 2 and one LRGS collaboration with USM and UNISZAR. He is the project leader for all these grants. The total amount of these research grants are more than RM 2.5 million. One of his research product has been commercialized through UTM Spin off company. This is supported by UTM Symbiosis programme which is the collaboration between UTM and MTDC. The total amount of grant obtained from this programme is nearly RM 2 Million. Through research, which he has conducted throughout the years, he has been honoured with recognition nationally as well as internationally for the products invention. The total awards that he has received through national competition is 5 gold, 5 silver and 3 bronze. This include Malaysia Technology Expo (MTE 2007), International Invention, Innovation and Technology Exhibition (ITEX 2008) and The International Exposition of Research and Invention of Institution of Higher Learning (PECIPTA2009, 2011). For international competition his product manage to secure 4 gold, 4 silver and 3 bronze. The international competition is Seoul International Invention Fair (SIIF - 2008, 2009 and 2011). In addition, he has filed the patent for more than 20 products as a principal inventor. In year 2009 he was awarded as a best fundamental research project in CITRA KARISMA 2009. Meanwhile in 2010 he was the finalist for the best intellectual property award in CITRA KARISMA 2010. MOSTI also has appointed him as an expert assessor to evaluate the proposal application under Research Development and Commercialization He is the chapter chair of IEEE APMTTEMC Malaysian Section for year 2011 and 2012. During his term as a chapter chair, he is continously organised conference under the umbrella of IEEE APMTTEMC. The conferences that chapter organised are IEEE Radio Frequency Microwave (RFM 2011) and IEEE Asia Pacific Conference on Applied Electromagnetic (APACE 2012). He received his excellence service award in 2004 and 2011 for his contribution towards university excellence. He has supervised 10 Phd, 47 Master which includes thesis, project report, dissertation and 100 undergraduate 
students. 4 Phd and 42 Master students have been graduated through his supervision.

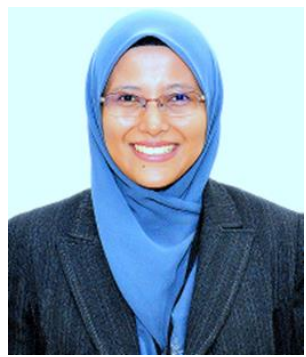

Noor Asmawati Samsuri received the B.Eng. (Hons) in Electrical-Telecommunication Engineering from Universiti Teknologi Malaysia in 2001, the MSc. in Digital Communications System from Loughborough University, UK in 2004 and the Ph.D. in Electronic and Electrical Engineering from Loughborough University, UK in 2009. She is presently a Senior Lecturer in the Faculty of Electrical Engineering, Universiti Teknologi Malaysia. Her research interests include wearable antennas including the interaction with human body and metallic items, implantable antenna for medical telemetry, and Specific Absorption Rate (SAR). During her carrier, she has been authored or co-authored several technical papers and book chapters related to her research interests. She has also been appointed as a reviewer for several journal papers at National and International level. Noor Asmawati Samsuri is a member of Board of Engineer Malaysia (BEM) and a member of IEEE (MIEEE), and is currently supervising a $\mathrm{PhD}$, Master and Undergraduate students

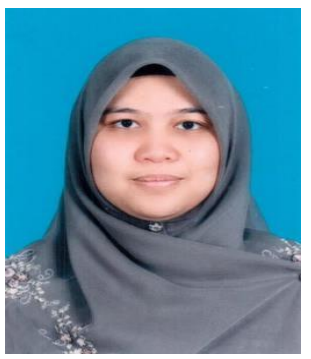

Kamilia Kamardin received her B.Eng. Electronic (Communications) from the University of Sheffield, U.K., in 2004 and obtained her M.Sc. in Information Technology (Data Communications and Networking) from Universiti Teknologi Mara (UiTM), Malaysia in 2007. She received her Ph.D. in Electrical Engineering (Communications) from Universiti Teknologi Malaysia (UTM), Malaysia in 2014. She spent 3 months at University of Bimingham, U.K., as a visiting Ph.D. student. She has previously served as a senior assistant researcher at TM Research \& Development, Malaysia for 3 years. Currently she is a senior lecturer at Universiti Teknologi Malaysia, Kuala Lumpur. She serves under Computer Systems Engineering Group at Advanced Informatics School. Her research interests include antennas, wireless communication, wearable communication, body centric communication, metamaterials, wireless networking, Internet of Things (IoT) and computer systems engineering. 